\title{
Semantic Reanalysis and Language Change
}

\author{
Regine Eckardt* \\ University of Göttingen
}

\begin{abstract}
Reanalysis is a well-known process of language change in morpho-syntax. However, the semantic composition of sentence meanings can also undergo reanalysis and lead to meaning changes for parts of the sentence. The article provides the basic notions of compositional semantics/pragmatics that underlie semantic reanalysis, surveys possible constellations and causes of reanalysis, and contrasts the process to other ways of semantic change. I will, moreover, illustrate semantic reanalysis on basis of a case study which highlights some of its typical features.
\end{abstract}

\section{Meaning Change and Grammaticalization}

Many people enjoy the fascinating task of tracing the history of words and expressions. Meaning changes often allow insights in cultural history, and major processes of change can be observed both in history and in daily life. For instance, speakers can decide to restrict the use of a word to what was formerly just the most frequent referents, like in Old English mete ('food') which turned into modern meat (food like in 'steak'). This is called semantic narrowing, and we will use the example to introduce a few convenient notations.

I will use $[[\alpha]]$ to refer to the meaning of a word $\alpha$, e.g. $[[\operatorname{dog}]]$ stands for the meaning of the word $d o g$. If the meaning of a word changes, we will use indices to indicate the two different meanings. Our instance of narrowing looks as follows: $[[\text { mete }]]_{\text {old }}$ was the concept 'food' or 'meal' in general, whereas $[[\text { mete }]]_{\text {new }}$ is the narrower concept 'meat, edible muscle matter of animals'. If we consider more than one shift in meaning, we will use numbers as indices. For instance, we will later discuss three subsequent meanings of German fast, notated as $\left[[\text { fast } t]_{1}\right.$, $\left[[\text { fast } t]_{2}\right.$ and $[[\text { fast }]]_{3}$. Other wellknown meaning changes include generalization, like for instance when $[[d o g]]_{\text {old }}=$ 'special breed of dogs' was extended to $[[\operatorname{dog}]]_{\text {new }}=$ 'species canis'. Furthermore, we know metaphoric extensions, like $[[\text { mouse }]]_{\text {old }}=$ 'small rodent' to $[[\text { mouse }]]_{\text {new }}=$ 'computer control', and also metonymic extensions, for instance when $[[\text { press }]]_{\text {old }}=$ 'machine for printing' generates the newer sense $[[\text { press }]]_{\text {new }}=$ 'newspapers'.

Other cases of language change are fascinating in other ways. When content words turn into grammatical words or morphemes, it is much less clear how speakers arrive at meanings as abstract as those of tense morphemes, auxiliaries, evidential markers or quantifiers. What exactly happens when a phrase he is at hunting changes its message from $[[\text { Tom is at hunting }]]_{\text {old }}=$ 'Tom takes part in a hunting event' to $[[\text { Tom is a-hunting }]]_{\text {new }}=$ 'at the time of reference, Tom hunts'? How does the overall shift in the message project back to the parts, in particular to the interaction of be and -ing, to yield a progressive aspect marker? Changes like this have been studied as grammaticalization of words or complex expressions (Hopper and Traugott 2003). The ensuing changes in morphosyntax are usually clear and well-understood. What happens at the semantic side, however, often 
cannot be classed easily under the four types above. Another fascinating puzzle is posed by isolated language changes which fit neither of the common types. For instance, how did it happen that premis(s)es, known to the logician as 'the assumptions in a deductive argument', in English also means 'house, estate'? The two concepts are not related metaphorically or metonymically, and the two senses don't generalize or narrow down each other, either. The present article will describe how semantic reanalysis as a mechanism of language change can help to model and understand semantic changes like these.

As later examples will suggest, semantic reanalysis can in principle affect any part of a sentence, and may or may not come along with morphosyntactic restructuring. However, many instances of language change which have been discussed in the literature, and where this process plays a role, are instances of grammaticalization. I will therefore briefly introduce some core concepts of the field without aiming at a full survey. ${ }^{1}$ Reviewing many examples of grammaticalization, scholars discovered so-called clines or pathways of grammaticalization. These are ordered series of denotations $\alpha_{1}, \ldots, \alpha_{n}$ such that several word forms $w, w^{\prime}, w^{\prime \prime}$ have been found which exhibit these meanings one after another: At some time $t,[[w]]_{\text {old }}=\alpha_{\mathrm{i}}$ and at a later stage $t^{\prime}$, there is a use $[[w]]_{\text {new }}=\alpha_{\mathrm{i}+1}$ in addition to $[[w]]_{\text {old }}$. The older use may get lost over time, but often also persists. Some words can travel the full series $\alpha_{1}$ to $\alpha_{\mathrm{n}}$ but others might only cover a subseries. What is important is that clines are almost always passed unidirectionally, which means that there is no known word $v$ that showed up with $[[v]]_{\text {old }}=\alpha_{i+1}$ before it developed $[[v]]_{\text {new }}=\alpha_{\mathrm{i}}$. Clines are viewed as typological universals, which means that there could be, and often actually are, words from more than one language that developed meanings along the cline. ${ }^{2}$

Collections of clines (like Heine and Kuteva 2002) help to catalogue regularities in grammaticalization even though they do not by themselves offer an explanation why the respective semantic positions show up in a specific order. Clines can also illustrate in what sense grammaticalization is a non-volitional type of language change. If some language, say, English, contains a word $w^{\prime \prime}$ in a sense $\left[\left[w^{\prime \prime}\right]\right]=\alpha_{\mathrm{i}}$ on a known cline, this does not mean that English speakers can volitionally start to use $w$ " in the next sense $\left[\left[w^{\prime \prime}\right]\right]=$ $\alpha_{i+1}$. For instance, English possesses the verb become. This verb shares its meaning with Old German werden which developed a use as a future modal. So, English become and German werden share a position on a cline. Nevertheless, English speakers could never use a sentence Italy becomes (to) win in the same futurate sense as its German word-by-word translation Italien wird gewinnen. Data suggest that semantic changes on clines often rest on a typical kind of sentence context in which the crucial word was used. German future werden, for instance, most likely developed in sentence contexts like 'He became (a) killed (man)', under the new interpretation that the participle ('killed') is no longer interpreted as part of an object NP but as part of a verbal complex with futurate meaning (Behaghel, 1924). While the syntactic reorganizations are usually quite clear, the semantic shifts eluded analysis for more than 100 years. Only since the advent of detailed compositional semantic analyses (prominently in the framework of truth conditional semantics) was it possible to trace and spell out the semantic reorganization of constructions (Eckardt 2006, 2003). I will first offer an abstract definition of the process and we will then turn to examples.

\section{Semantic Reanalysis}

We follow Frege's classical assumption that language is compositional: The meaning of larger phrases and sentences is composed systematically from the meaning of its syntactic constituents. If a sentence $S$ is hence built up from parts $\omega_{1}, \omega_{2}, \ldots, \omega_{\mathrm{k}}$, then its meaning 
$[[S]]$ is construed by combining the meanings of these parts in the intended order: $[[S]]=$ $\left[\left[\omega_{1}\right]\right] \oplus \ldots \oplus\left[\left[\omega_{\mathrm{k}}\right]\right]$. Here, $\oplus$ stands for semantic composition in general. If you are acquainted with truth conditional semantics, you can mostly read $\oplus$ as 'functional composition'. The parts $\omega_{1} \ldots \omega_{\mathrm{k}}$ comprise all meaningful parts of $S$, be it words, morphemes, or sometimes also tacit semantic operators. For instance, the sentence John ate the beans has the parts John, eat, PAST, the and beans. Syntax will drive the order of combination, hence the is the determiner to beans, the beans is the object of eat and John its subject, etc. Assume now that $S$ is understood in a new sense $[[S]]_{\text {new. }}$. Assume that the parts of $S$ are still $\omega_{1}$ to $\omega_{\mathrm{k}}$. This forces the hearer to assume that at least one of these parts $\omega_{\mathrm{j}}$ must also have a new meaning $\left[\left[\omega_{\mathrm{j}}\right]\right]_{\text {new }}$ or else, the speaker meant to convey her message $[[S]]_{\text {new }}$ in a non-compositional manner. ${ }^{3}$ At this point, $\omega_{\mathrm{j}}$ changes its meaning due to semantic reanalysis. Generally, semantic reanalysis follows the maxime 'guess meaning by subtraction'. The overall message [[S]] is known. The meanings of almost all parts of $S$, $\omega_{1}, \ldots \omega_{\mathrm{k}}$ except one $\omega_{\mathrm{j}}$ are also known, and the hearer also has an idea about the syntactic structure of $S$, which determines the order of semantic composition. The hearer must answer the following question:

$(*) \quad[[S]]=\left[\left[\omega_{1}\right]\right] \oplus \ldots \oplus\left[\left[\omega_{\mathrm{j}-1}\right]\right] \oplus<\mathrm{X}>\oplus\left[\left[\omega_{\mathrm{j}+1}\right]\right] \ldots \oplus\left[\left[\omega_{\mathrm{k}}\right]\right]$

What semantic value $<\mathrm{X}>$ will make this equation work?

Whenever a word, morpheme or construction $\omega_{\mathrm{j}}$ is used in a new meaning $\left[\left[\omega_{\mathrm{j}}\right]\right]_{\text {new }}$ in answer to a question like $\left(^{*}\right)$, I'll say that $\omega_{\mathrm{j}}$ adopts a new meaning due to semantic reanalysis. Note that this definition is intended in a wide sense. The question $\left(^{*}\right)$ can arise because the hearer understands a new message for $S$, or because he interprets on basis of a new syntactic structure, or reassignment of pragmatic values. Let us see some examples.

In the simplest case, an old message is restructured in a new way. The NP the premises as a way to refer to houses and buildings arose in this manner. According to the Oxford English Dictionary (OED), the noun premise originally was anaphoric: 'The matters or things stated or mentioned previously; the aforesaid, the aforementioned, the foregoing. Often (...) in legal phraseology' (OED, premise 2.a.). In stereotypical advertising contexts, this anaphoric element was used to refer to houses: 'In $p l$. The subject of a conveyance or bequest, as specified in the opening part of a deed and referred to later in the document; the houses, lands, or tenements previously specified in a deed or conveyance.

(1) All which maners, londs, and tenements, and other the premisses, we late purchased'. (1508 in Nichols Royal Wills 379, OED 3.a.)

In semantic reanalysis, the anaphoric status of the NP was given up in favor of a contextindependent definite expression for larger units of housing (OED, premise 3.b). Reanalysis happened on basis of examples like (1508): ... we purchased the premis(s)es, and the minimal new assumption of the hearer was that premise was an ordinary noun, rather than a high register anaphoric element.

$[[\text { the premisses }]]_{\mathrm{old}}=$ anaphoric element, instantiated in context by the 'estate'

$[[\text { the premisses }]]_{\text {new }}=$ definite $\mathrm{NP}$, denoting a given estate

In other cases, morphemes can get grouped in new ways in morphosyntax. The German preposition während ('during') goes back to a present participle of the verb währen ('last', 'continue') in constructions where it shows agreement with a masculine genitive noun: 
währendes $_{\text {Participle }}$ Krieges $_{G E N}>$ während $_{\text {preposition }}$ des $_{\text {det }}$ Krieges $_{G E N}$ ('lasting war' $>$ 'during the war'). Again, the overall meaning of the new-born PP was clear, leading the hearer to assign a new prepositional meaning (='during') to the new-born word während.

$$
[[\text { während }[\text { des Krieges }]]]=<\mathrm{X}>\oplus([[\text { des }]] \oplus[[\text { Krieges }]])
$$

In grammaticalization, hearers typically understand a new sentence meaning that differs from the original $[[S]]$ in subtle ways which force semantic reanalysis. When hearers took sentences like [[She is going to be married]] as a report about future events, rather than about present movements, this invited them to also assume that going (to) contributed to the sentence meaning in a new way (Hopper and Traugott 2003; Eckardt 2006, ch.4).

$$
\begin{aligned}
& {[[\text { She is going to be married }]]_{\text {new }}} \\
& =[[\text { She }]] \oplus[[\text { be }]] \oplus[[\mathrm{PRESENT}]] \oplus(<\mathrm{X}>\oplus[[\text { to be married }]]) \\
& <\mathrm{X}>=[[\text { going }]]_{\text {new }}
\end{aligned}
$$

In this case, it was most likely the meaning shift that forced a reorganization in syntax from biclausal going $+\left[\begin{array}{lll}\text { to } & d o & z\end{array}\right]_{\text {S-inf }}$ to the monoclausal going-to do $z$ construction. The emergence of prepositional während, in contrast, arguably was caused when hearers replaced a pretty baroque, archaic pattern in German, "free genitive circumstantial modifier', by the more common PP pattern. Here, syntactic analogy was a driving factor. The premise case, finally, caused no syntactic change at all. Our range of examples shows that semantic reanalysis is an autonomous mode of change. It can cause, or be caused by, changes in morphosyntax, and sometimes happens all on its own.

As can be seen from these examples, semantic reanalysis necessarily takes place in a sentential context, though not necessarily only in cases of grammaticalization. Scholars have always been curious about what kind of context is endangered by semantic reanalysis. Heine (2002:86) refers to such contexts as bridging contexts, and suggests that metaphoric interpretations could be the driving force. However, the semantic shifts in grammaticalization are rarely of a kind that one would naturally call metaphors. Particularly, bridging contexts are typically not instances of innovative creative language use (as would be typical for metaphor) but uses that are simply ambiguous between an older and a newer interpretation - with the newer structure only unambiguously visible somewhat later in the data. Diewald (2002) addresses them as critical contexts. When we look into historical data, an utterance $S$ is critical for an expression $\omega_{\mathrm{j}}$ primarily if $\mathrm{S}$, in the given text passage, makes sense both on basis of $\left[\left[\omega_{\mathrm{j}}\right]\right]_{\text {old }}$ and $\left[\left[\omega_{\mathrm{j}}\right]\right]_{\text {new }}$. Note that $\omega_{\mathrm{j}}$ can also change its morphosyntactic category in the reanalysis. Diewald (2006) proposes that critical contexts are in fact constructions in the sense of construction grammar, i.e. pairs of an expression and a meaning $\langle e, m\rangle$ where $m$ is attributed to $e$ without further semantic composition. Only later, she suggests, will speakers attempt to decompose $e$ and assign parts of $m$ to the subexpressions of $e$. We see that this has happened when we encounter quotes which only make sense on basis of $\left[\left[\omega_{\mathrm{j}}\right]\right]_{\text {new. }}$. They prove that the change has taken place and are called isolating contexts by Diewald. I do not want to take a stand as to whether such intermediate idiomatic uses can or can not happen. Some developments, as Diewald's case of modal verbs in German, may show a data record which suggests an intermediate idiomatic use of certain modal constructions. However, other data records do not show similar phases, suggesting that semantic reanalysis can also occur on basis of more varied ambiguous usages. We will see an example later in the paper. 
If you observe your own communicative activities, you will find it hard to locate sentences you read or hear where you'd have the impression that they are ambiguous (in the structural/semantic sense that is at issue here) or that you don't really understand them. Nevertheless, we can safely assume that the critical contexts for tomorrow's language changes are around us today. So we need to tackle the question what causes a hearer/reader to assume that the speaker didn't intend to use sentence $S$ in the conservative sense but in a new one? Eckardt $(2006,2009)$ suggests that sentences $S$, intended in conservative language use, can carry a pragmatic overload. To put it simply, $S$ in the conservative sense and structure would be so hard to interpret and make sense of that the hearer feels justified to believe that the speaker meant to use $S$ in some new sense. Such uses of S are called precarious uses in Eckardt (2009), and we will see examples later in the article. 'Precarious' means that the utterance was not really wrong, but it was risky way for the speaker to convey her message. ${ }^{4}$ Precarious contexts may in part overlap with Diewald's critical contexts, but the term is intended to suggest that the utterance stretched the limits of the conservative grammar system. (Another differenc is that precarious contexts can spur changes beyond grammaticalization, whereas Diewald appears to restrict attention to grammaticalization.) Pragmatic enrichment has been suggested as another process that leads from old literal to new literal content (Traugott 1988; Traugott and Dasher 2002), but given that pragmatic enrichments are standardly available anyway, one may wonder why pragmatic enrichment should lead to language change rather than to a semantically flexible but overall stable system.

In summary, semantic reanalysis offers a viable explanation for semantic change in sentential contexts, rare directions of change and infrequent or singular patterns. It typcially can't be actively reinforced, and in this differs from metaphor or metonymy. Scholars and case studies suggest that semantic reanalysis can

- be triggered as a by-product of structural reanalysis which, in turn, may be independently motivated (e.g. less complexity, Lightfoot 1991, modifier-head reanalysis, van Gelderen 2008)

- be spurred by analogy (Fischer 2007)

- be triggered by the urge to avoid pragmatic overload (Eckardt 2009)

- be triggered by the urge to conventionalize pragmatic enrichment (Traugott and Dasher 2002).

In the next section, we will look into one case study in more detail.

\section{3. 'Almost' by Reanalysis}

Words with the denotation 'almost' are often derived metaphorically from words that express spacial closeness ( $\mathrm{G}$ bei-nahe, $\mathrm{E}$ nearly, $\mathrm{F}$ prèsque). However, other sources have been pointed out, including changes 'badly' > 'almost' (Amaral, 2006), and 'similarity' > 'almost' (Kytö and Romaine 2005). I will use two German examples here, schier and fast, to illustrate semantic reanalysis, specifically the non-productive character of reanalysis, the context-dependency of reanalysis, and the pattern of precarious uses that antedate and accompany the time of reanalysis.

In Southern German varieties, the adverb schier can be used to express 'almost':

(2) Der ist schier gestorben vor Angst 'He almost died for fear' 
The word can be traced back to a temporal adverb schier that meant 'soon'. Probably contexts of change are temporal constructions where at a given reference time, some future state of affairs 'will soon be reached' = 'has almost been reached'.

(3) da nam Thobias von der gallen des visches, er salbet die there took Tobias of the gall of-the fish he anointed the augen seines vaters, eyes of-his father und er geduldet es schier ein halbe stund. and he bore it soon a half hour Bible of 1483, (Tobias 11, 13)

Interestingly, Luther's bible (1534) uses fast in the same passage. Grimm's Deutsches Wörterbuch (DW) hypothesizes that the new sense schier new arises from uses like the following.

(4) Als wir schier an 3 Stunden getaget hatten... when we soon by 3 hours conferenced had

Let us see how two different syntactic-semantic analyses of (4) can be given on basis of the word's older and newer sense. Both propositions state that at the reference time, a conference of nearly 3 hours length had taken place.

$$
[[S]]_{\text {old }}=[\text { als schier }[\text { wir hatten an } 3 \text { Stunden getaget }]]
$$

In the semantic composition, the word schier relates a proposition $p$ to a time $t$. $\operatorname{SoON}(t, p)$ is true iff $p$ is false at $t$ but becomes true at some time soon after $t$. In the given example

$$
[[S]]_{\text {old }}=\operatorname{SoON}(\mathrm{R}, p)
$$

where $R$ is the reference time, $p$ is the proposition "we met for 3 hours ${ }^{5}$

However, a different way of making the same point is this: 'when we had met for nearly 3 hours'. And maybe, this is even a more down-to-earth way of talking, compared to statements about propositions that would soon be true. Understood in this sense, the hearer faces the following semantic composition:

(\#) $\quad[[S]]_{\text {new }}=p$ is true at $R$ where $R$ is the reference time, $p$ is the proposition 'we met for almost 3 hours'

She would hypothesize the following compositional structure:

$$
\text { [als[wir hatten[schier an } 3 \text { Stunden }] \text { getaget }]]
$$

and find that $[[S]]_{\text {new }}$ can indeed be composed from the old parts $[[a l s]]_{\text {old }}$, $[[\text { wir }]]_{\text {old }}$ etc. apart from one step: There is a superfluous word schier, and a necessary semantic operator $<\mathrm{X}>$ = Almost that is needed to reach (\#). I assume a polymorphic analysis of 'almost' which can combine with arguments of different logical types (Penka 2006, Eckardt 2007). The most natural idea for the hearer will be to assume that $[[\text { schier }]]_{\text {new }}=$ Almost. I'd like 
to stress that the two denotations $[[\text { schier }]]_{\text {old }}$ and $[[\text { schier }]]_{\text {new }}$ are truly distinct, as you can easily test by comparing, e.g. English soon and almost, or German bald and schier.

Let us now turn to another case, the development of Modern German fast 'almost'. Like its English cognate fast ('quick'), it derives from an older adjective/adverb fast with the sense 'solid, fixed, firm'. The oldest quotes show vast/fast to express physical firmness but the word was metaphorically extended to psychological determination, firm pursuit of a task. From there, it was generalized to intenseness, and high degree. Around 1400, uses of fast often translate to English very much, determinedly, energetically. In ModHG, fast has completely lost this sense. The variant fest is used to express physical firmness.

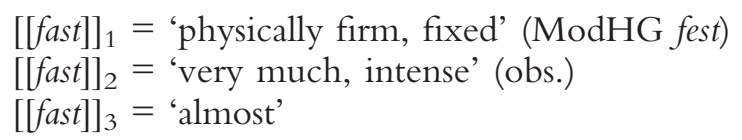

Older and newer denotations are almost contradictory. If a thing is "firmly attached to something', it is simply not 'almost attached', and likewise if a person does something 'intensely', that person simply doesn't do the thing just 'almost'. Philologists occasionally take such examples as evidence for a general weak-mindedness of ordinary speakers, but I do not think that this diagnosis does justice to the human language capacity. I want to argue that the modern meaning $[[\text { fast } t]]_{3}$ arose by reanalysis at a time where precarious uses of $[[\text { fast } t]]_{2}$ increased. In the following, I will use fast old $_{\text {and }}$ fast $t_{\text {new }}$ to refer to these two uses.

The authors of the DW state that 'isolated uses (of fast) in 16/17th century slip towards [the 'almost'] sense' without speculating about the kind of context or reason why these slips occur. The most concise claim in this direction is made with respect to a quote fast um zwo uren ((we arrived) at almost 2 o'clock), and the DW states that the author conveyed 'ungefähr, gerade um zwei uhr, weil hier die bestimmtheit leicht an unbestimmtheit grenzt'. ${ }^{7}$ I find such statements dissatisfying, because I can not see how exactness can overlap conceptually with vagueness. More objectively, perhaps, the quoted studies on sources for words that mean 'almost' do not list a second instance of this semantic shift whereas sources like 'similarity' or 'temporal closeness' reappear more frequently.

What is in fact typical about this quote is that vast/fast old 'very much' would have required a gradable argument to combine with, whereas a time point like zwo uren can not be graded. (In terms of Diewald, the quote shows an isolating context, not a critical context.) Other non-gradable arguments that occur early with fast include the quantifier alle where again, 'almost all' is a reasonable semantic combination whereas 'very much all' would be semantically defective (Kennedy and McNally 2005). We can hence use vast alle as indicators of early uses of fast $t_{\text {new }}$. Using the source text section of the DW as a search base, I looked up the collocation vast alle to verify the dictionary's estimate for early occurrences. (The older spelling variant vast was given up after 1800; it avoids hits in ModHG). The search yields 13 hits of which 12 date after 1500. An early quote from 1314 remained isolated in all later searches and I do not take it as an indication for a much earlier language change. A fuller search of the DW sources for vast yields 797 hits altogether, including a few double hits. The manually surveyed hits 1-200 reveal that those usages of vast that are dubitable, ambiguous, or clearly 'almost' uses all date after 1500 . The time boundary 1500 is confirmed by open Google search for 'vast alle' (19.5.2010). An evaluation of first 100 hits yields 33 uses in Early ModHG texts; all after 1500, and a substantial portion even much later. Based on this evidence, we can preliminarily conclude that fast new $_{\text {appeared after } 1500 .}$

This is corrobated by the Bonner Frühneuhochdeutsch-Korpus, specifically the sources before 1500. These early sources contain 136 uses of fast/vast, among which only 
3 are unclear uses, and zero uses in the sense 'almost', which confirms that fast $t_{\text {new }}$ was not in use before 1500. The spelling situation looks as follows: There are 87 hits of the form vast(e), 70 of the form fast(e), but the latter include 60 hits in one document alone, hence idiosyncratic to its author. Excluding these, we have a 87:10 ratio between vast:fast spellings which indicates that vast was common if not predominant at the critical time.

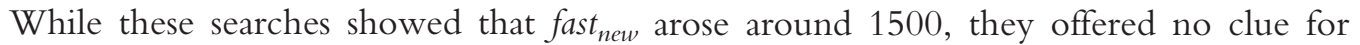
the source construction. We'll therefore turn to Flugschriften gegen die Reformation, 1518-1524 (FgR, Laube and Weiss (eds.), pamphlets that were addressed to the educated public and argued against Luther's reformation). In a total of 47 uses of fast/vast in these pamphlets, 2 clear uses show the new 'almost' sense, 2 uses are ambiguous between 'very' and 'almost', 9 uses are precarious. All quotes date from 1518 to 1524 and were written by preachers. The pamphlets show a mix of conservative, innovative, and precarious uses, quite typical when language change is under way. Let us first look at two clear uses of fast $_{\text {new }}$ :

(5) ... dermassen es nun fast Quinta essentia worden ist ... (FgR p. 90) such-that it now almost quinta essentia become is 'such that it is by now almost quintessential'

(6) ... die selbige seint yrer handwergk halben fast alle $z u$ the same are (for) their craft's cause almost all to betlern worden ... beggars become 'these have almost all turned to beggars, for their craft's sake' (FgR p. 662)

In both cases, fast plausibly takes an argument that is not gradable ('become quintessential', 'all become beggars'). Such an argument couldn't combine with the intensifying adverb fast $t_{\text {old }}$ 'determinedly, very'. The second passage moreover continues talking about other people who did not turn beggars but earn money with sinful occupations instead. This contrast likewise suggests an 'almost all' interpretation. This shows that two authors had adopted fast $t_{\text {new }}$ in their mental lexicon.

More frequent were uses of fast old in precarious constructions. The following passages contain the collocation fast... alle but are intended as conservative uses. A reanalysis in the 'almost' sense could be possible in both cases. However, the overall text passages do not suggest that the authors were talking about 'almost, but not all N'.

(7) Ain gegenwurff, darauff die feind der kirchen fast all a counter-thesis on-which the enemies of-the church fast all ir grund setzen.

their reasons put

'a counter-thesis on which fast all enemies of the church build their reasoning' (FgR, p. 734)

In a conservative interpretation, the author used fast old 'fixedly' as a modifier of setzen ('put fast'). However, the modifier is separated from the verb by a definite NP. While adverb positions are very flexible in Early ModHG, definites tend to be placed before manner adverbs. Hence, syntax suggests an alternative structure in which fast modifies the 
NP all ir grund. This excludes fast old for semantic reasons, and can at least raise doubts in the reader as to what the author intended to say.

(8) (one should not say anything against selling indulgences)

... welches doch fast in allen artickeln geschieht.

which PRT fast in all articles happens

'which however happens fast in all articles'

(FgR, p. 61)

If we look for an argument for fast $t_{\text {old }}$, the verb 'happen' seems the only potential candidate. What the author seems to have had in mind is a combination of fast old with the antecedent of anaphoric geschieht: 'in all articles, people argue determinedly against selling indulgences'. However, this reading is only accessible after anaphor resolution; moreover the modifier fast is again separated from its argument. Syntax suggests a combination (fast + 'in all papers'). This can only be interpreted in terms of fast new. However, I suspect that the writer once more simply put things in a precarious way, as the surrounding text does not suggest an 'almost' reading.

While the previous examples show precarious uses of adverb plus verb, other quotes show that a propositional use was established at the time.

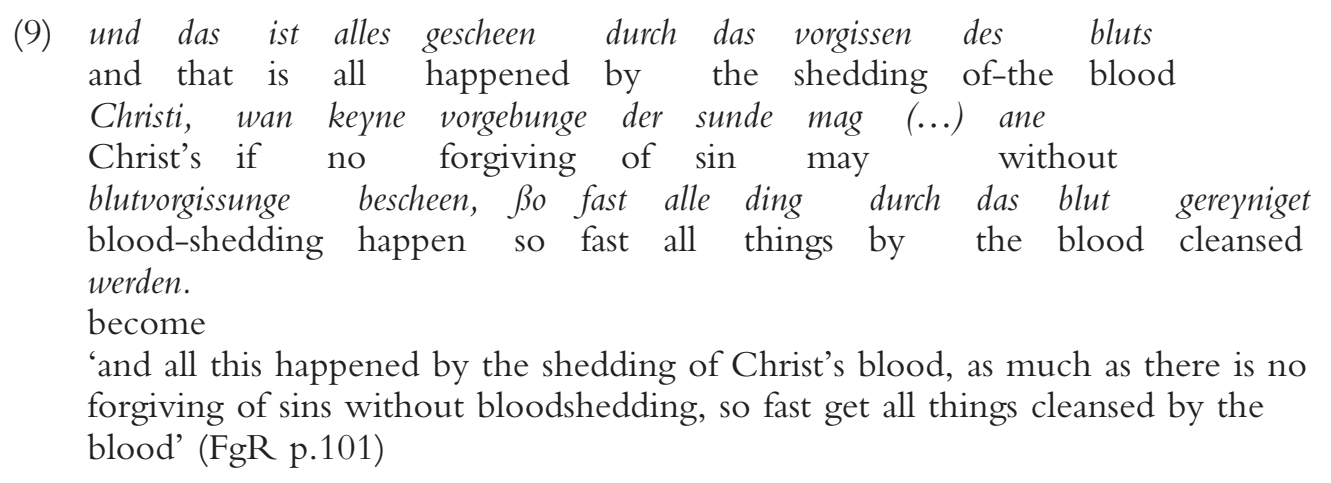

Once again, fast precedes a quantified NP. A verb-modifier reading yields the proposition 'all things get very much cleaned by Christ's blood'. However, the theological notion of being clean from sins is not gradable, and the proposition therefore implausible. In terms of linguistic structure, fast $t_{\text {new }}$ yields a plausible reading: [fast $t_{\text {new }}+$ all things] get cleaned by Christ's blood. This message, however, would be even more heretical, as no $\sin$ is too bad to be cleansed by Christ's blood. The author hence must have intended a proposition oriented reading: 'as much as no sins can be forgiven without Christ's blood', $\beta o$ fast $=$ so much/certainly will all things be purified by the blood.' The author attests that the proposition 'all things get cleansed by Christ's blood' a high degree of truth.

While this may be logically senseless, the concept exists in many languages. Interestingly, the notion of something being 'very true' can apply to non-gradable as well as gradable content as illustrated by an example from ModE:

(10) As much as the Queen is the leader of the UK, she still has to obey the law.

'It is very true that the Queen is the leader, but still ...' 
I will not expand this into a full analysis, but the construction offers a possibility to combine 'very much' with sentences that do not themselves refer to grades. More quotes of this kind are added in an appendix.

The quotes from FgR show that speakers/writers used fast old $_{\text {in }}$ in sentences that were quite varied (and hence don't exhibit one uniform type of construction) but all share the fact that they were somewhat unperspicuous. Specifically, it is propositional uses in the sense of 'it is very true that $p$ ' which often contain fast old with a sister constituent that doesn't denote a gradable concept. The writers most likely intended, and readers could still interpret the utterence based on fast old. Alternatively, at least some of these cases could also lend themselves to a semantic composition with fast $_{n e w}$. A reader who saw this alternative way of semantic composition could hence believe that other speakers used fast in a new sense that was not yet part of his/her own mental lexicon. We simply need to find examples that could suggest a new meaning fast $t_{\text {new }}=$ 'almost' to such uncertain hearers/readers. Let me offer several suggestions about potential places for reanalysis.

In some cases, negation of high degrees results in an 'almost' reading. The following quote exemplifies the constellation.

(11) es ist nit fast nutz ...

it is not fast useful

(FgR, p. 558)

A conservative narrow scope LF ['not' [fast old + 'useful']] yields the statement that something is 'not very useful'.

[[es ist nit fast nutz] $]_{\text {old }}=$ 'its degree of usefulness is not very high'

The reader might understand the stronger message that the thing in question is 'almost useless'. This message can feed a reanalysis into the new LF [fast new + ['not useful'/ 'useless']].

[[es ist nit fast nutz $]]_{\text {new }}=$ 'it is almost useless'

reanalysing $[[\text { fast }]]_{\text {new }}=\lambda \mathrm{P} \cdot \operatorname{ALmost}(\mathrm{P})$

Another option could be reanalysis triggered by scalar implicatures. Intensifying fast is often combined with other intensifying constructions, like in the following example:

(12) sei rouften laut, sei schrewend fast

they called loudly, they screamed fast

Heinrich Wittenwiler, Der Ring (c. 1408/10), part I, 1. 352

This example is pragmatically precarious. Arguably, schrewen ('scream') is a more intense variant of roufen ('call'). roufen can be intensified to rouften laut which, by itself, gives rise to the scalar implicature 'they didn't do anything more intense than call loudly'. The subsequent statement that they also schrewend fast ('scream very much') can be interpreted conservatively, and hence cancel the implicature. However, the reader/hearer could also be led to assume an alternative rhetorical structure in which the second conjunct elaborates the first:

they cried loudly, they almost screamed 
If this were the understood message, the hearer would again infer a (new) lexical entry $[[\text { fast }]]_{\text {new }}=\lambda$ P.ALmost $(\mathrm{P})$.

Finally, there could be reanalysis from the propositional 'as much as it is true that ...' operator to an 'almost' operator which only takes low scope over its argument all 'all'. The following quote illustrates this. In the present example, reanalysis exploits a discours use of $s o=$ 'given that'.

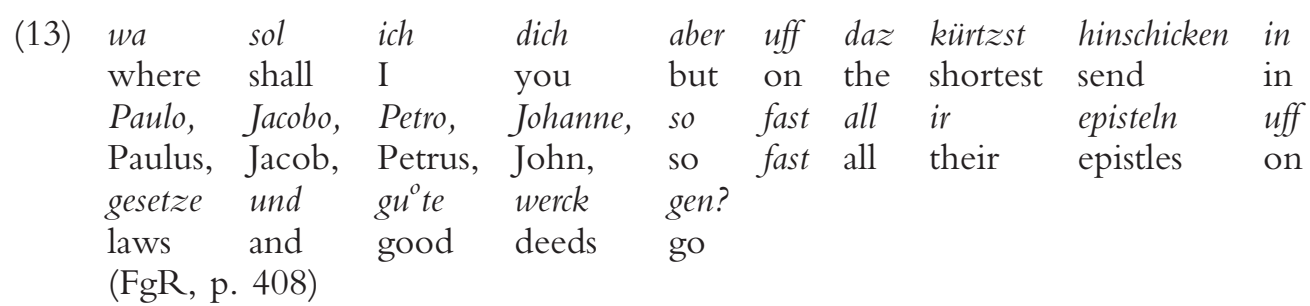

The author wants to back up an earlier claim by a supporting quote from the New Testament which, as stated, contains plenty: which one should he pick? In a conservative interpretation, the author wrote "where should I direct you - as much as it is true that all epistles are about laws and good deeds?' i.e. a rhetorical gesture of helplessness. (Lutherans were commonly better read in the bible than Catholics.) An alternative interpretation would essentially make the same point: 'Where should I direct you, given that almost all their epistles aim towards laws and good deeds?'.

$\mathrm{LF}_{\text {old }}$ : [so fast [all epistles go for laws and good deeds]]

$[[S]]_{\text {old }}=$ 'as much as it's true that $p$ '

$p=$ 'all their epistles aim towards laws and good deeds'

$L_{\text {new }}:$ [so [[fast all epistles] go for laws and good deeds]]

$[[S]]_{\text {new }}=$ 'as (almost all) their epistles aim towards laws and good deeds'

reanalysing $[[\text { fast }]]_{\text {new }}=\lambda \mathrm{P} \cdot \operatorname{Almost}(\mathrm{P})$

Potential sources for reanalysis might have occasionally occurred at all times, but they gained momentum when the general spectrum of uses of fast in all its older senses had become wide, and when precarious (older) uses seem to increase. ${ }^{9}$ I took this final, lengthy example to illustrate not only semantic reanalysis as a process, but also the linguistic and communicative landscape in which semantic reanalysis occured.

\section{More Research, Past and Future}

This article intended to show how hearers arrange and re-arrange meanings when they interpret an utterance. Such re-arrangements can lead to persisting language change. Semantic reanalysis is an independent mode of semantic change, next to other, betterdescribed changes like metaphoric extension, metonymy, narrowing or broadening. Semantic reanalysis is one more phenomenon in languages which wittnesses speakers' trust in semantic composition. With its focus on composition, the approach allows us to better understand the unconscious reasoning of the hearer/reader in the phase of change, as well as the communicative situations that spur such reasoning. I suggested that precarious uses 
of words can invite hearers to reanalysis. More cases illustrate this point, like lauter (Eckardt 2006), even (Traugott 2006, Eckardt 2009), selbst (Eckardt 2006) and it is indirectly advocated by authors who warn against teleological models of change: language change is not an automatism which carries languages towards an ideal end state.

Semantic and pragmatic formats that reflect semantic composition at an appropriate level of detail are indispensible in understanding the laws and limits of semantic reanalysis. Formal analyses can help to separate instances of generalization from instances of reanalysis (see Condoravdi and Deo 2008), investigate the semantics of functional terms in detail (Deo 2006; Gerö and von Stechow 2003; Haug 2008) and, finally, begin to understand the semantic and pragmatic contribution of grammaticised discourse markers (Zeevat and Karagjosova, 2009).

Such analyses also newly pose the question about pushing factors in language change. Researchers have suggested many reasons that might drive speakers/hearers to reform their internal grammars, ranging from laziness, or the need to increase the expressive power of one's language, over the desire to be original to the urge to simplify and systematize a local part of one's grammatical system. The present article is modestly restricted to the discussion of one particular mode of semantic change and I will therefore not attempt to weigh the reasons that spur semantic reanalysis against other driving forces of change. Taking a wider perspective, note that precarious language use can be precarious in many ways. It can challenge the hearer by pragmatic infelicities, by too rich background assumptions, by uncommon or archaic syntactic constructions, unusual operator-argument constellations in syntax, semantically baroqueness and maybe more. ${ }^{10}$ What remains typical, however, is that the semantic changes that affect parts of the utterance are determined 'top-down' by the hearer's attempt to understand how the overall message is built up in the sentence. These changes are therefore not necessarily driven by the semantic qualities inherent to the word or expression, e.g. by coercion or metpahoric potential. The changes can be minor, but can also span surprising conceptual gaps: For instance, Botne (1998) reports on Bantu languages where the verb say developed a second use as a future tense serial verb (something similar to an auxiliary, but in more complex interaction with the main verb of the sentence). It will be desirable, hence, to accumulate a representative range of detailed case studies before we can make out universal trends like semantic simplification, streamlining of the mapping between syntax and semantics, improvement of syntactic elegance or restructuring in analogy to other dominant patterns in the language, and before we can say which ones predominate as causes in change.

\section{Short Biography}

Regine Eckardt holds a doctorate from Stuttgart and is now Professor of Linguistics in the Department of English Language and Literature at Göttingen University. Building on her early research topics in synchronic semantics and pragmatics, she has been working on meaning change and grammaticalization since 2000. Specifically, she pursues the hypothesis that the paradigm of truth conditional, compositional semantics and pragmatics is particularly suited to analyse the shifts and changes of semantic composition in grammaticalization.

\footnotetext{
Notes

* Correspondence address: Regine Eckardt, English Department/Linguistics, University of Göttingen, KäteHamburger-Weg 3, D-37073 Göttingen, Germany. E-mail: regine.eckardt@phil.uni-goettingen.de
} 
1 The field will be comprehensively covered in Heine, B. and H. Narrog (eds.), Handbook of Grammaticalization, to appear at Oxford University press.

2 To be precise, I should mention that the positions on clines can often also include a syntactic characterization of the respective word(s). Being mostly concerned with meaning change here, I left these out. On the other hand, each semantic positions on a cline is usually loosely taken and might cover more than one denotation in, e.g. the strict sense of truth conditional semantics. Otherwise, chances are dim that any cline could actually be travelled more than once.

${ }^{3}$ Resort to non-compositional interpretation can happen, but for the sake of the discussion, I will stick to the conservative assumption that it doesn't in the cases at hand.

${ }^{4}$ Readers of Diewald (2002) will acknowledge that precarious contexts don't coincide with her atypical contexts either because these are characterized by standard pragmatic implicatures, not by pragmatic overload or markedness. Diewald (2006) is written against a background of construction grammar, and assumes that word and sentence meanings are more often non-compositional than not. I will not follow this assumption but have to leave a full justification for semantic compositionality to another occasion.

5 formally, $p=\lambda w \cdot \exists e\left(\operatorname{CONFERENCE}_{\mathrm{w}}(\mathrm{we}, e) \wedge \tau(e)=3 \mathrm{~h}\right)$.

6 formally, $p=\lambda \mathrm{w} . \exists \mathrm{e}\left(\operatorname{ConferenCE}_{\mathrm{w}}(\mathrm{we}, \mathrm{e}) \wedge \tau(\mathrm{e})=\operatorname{Almost}(3 \mathrm{~h})\right)$.

7 'The author conveyed exactly/almost at two o'clock because here, exactness borders easily to vagueness'.

8 An anonymous reviewer suggests that complex clause structure could play a role in this change. I currently see no direct connection, except perhaps the obvious correlation between overly complicated contents and overly complicated syntax. Any such hypothesis, hence, will have to be subject to future research.

9 It might be tempting to speculate that the speaker-hearer constellation in this particular type of text, written by theological experts for lay readers, likewise supported reanalysis. A verification of sociolinguistic claims requires electronic sources that are not, presently, available for German.

10 See Roberts and Roussou 2003 and Roberts 2010 for a recent discussion of cases where morphosyntactic facilitation is hypothesized to drive language change.

\section{Works Cited}

Amaral, Patricia Matos. 2006. The polysemy of 'mal' in European Portuguese: a diachronic analysis. Journal of Historical Pragmatics 7. 1-37.

Behaghel, Otto. 1924. Deutsche Syntax. Vol. II. Heidelberg: Winter.

Botne, Robert. 1998. The evolution of future tenses from serial 'say' constructions in central eastern Bantu. Diachronica XV.2. 207-30.

Condoravdi, Cleo, and Ashwini Deo. 2008. Aspect shifts in Indo-Aryan. Proceedings of the 18th International Congress of Linguists (CIL 18): workshop on formal approaches to the relation of tense, aspect and modality, 21-26 July, Seoul.

Deo, Ashwini. 2006. Tense and aspect in Indo-Aryan languages: variation and diachrony. Yale University, New Haven: PhD dissertation.

Diewald, Gabriele. 2002. A model for relevant types of contexts in grammaticalization. New reflections on grammaticalization, ed. by Ilse Wischer and Gabriele Diewald, 103-20. Amsterdam: John Benjamins.

- 2006. Context types in grammaticalization as constructions. $15^{\text {th }}$ Sept. $2010<$ http://www.constructions-online.de/articles/specvol1/686>.

Eckardt, Regine. 2006. Meaning change in grammaticalization. Oxford: Oxford University Press.

2007. Almost - an analysis. $17^{\text {th }}$ Sept. $2010<$ http://www.semanticsarchive.net/>.

- 2009. APO-avoid pragmatic overload. Current trends in diachronic semantics and pragmatics, ed. by Maj-Britt Mosegaard Hansen and Jacqueline Visconti, 21-42. UK: Emerald.

-, Klaus v. Heusinger, and Christoph Schwarze (eds). 2003. Words in time. Berlin: Mouton deGryuter.

Fischer, Olga. 2007. Morphosyntactic change: functional and formal perspectives. Oxford: Oxford University Press.

Gelderen, Elly van. 2008. Economy of merge and grammaticalization. Variation, selection, development, ed. by Regine Eckardt, Gerhard Jäger and Tonjes Venstra, 179-98. Berlin: Mouton deGruyter.

Gerö, Eva-Catrin, and Arnim von Stechow. 2003. Tense in time: the greek perfect. Words in time, ed. by Regine Eckardt, Klaus v. Heusinger and Christoph Schwarze, 251-94. Berlin: Mouton deGryuter.

Grimm, Jakob, and Wilhelm Grimm (eds). 1854-1960. Deutsches Wörterbuch. Leipzig: S. Hirzel.

Haug, Dag. 2008. From resultatives to anteriors in Ancient Greek. On the role of paradigmaticality in semantic change. Grammatical change and linguistic theory, ed. by Th. Eythorsson, 285-305. Amsterdam: John Benjamins.

Heine, Bernd. 2002. On the role of context in grammaticalization. New reflections on grammaticalization, ed. by Ilse Wischer and Gabriele Diewald, 83-102. Amsterdam: John Benjamins.

— and Tania Kuteva. 2002. World lexicon of grammaticalization. Cambridge: Cambridge University Press.

Hopper, Paul, and Elizabeth C. Traugott. 2003. Grammaticalization. Cambridge: Cambridge University Press. Second, revised edition.

Kennedy, Chris, and Louise McNally. 2005. Scale structure, degree modification, and the semantics of gradable adjectives. Language 82(2). 345-81. 
Kytö, Merja, and Suzanne Romaine. 2005. We had like to have been killed by thunder \& lightning: the semantic and pragmatic history of a construction that like to disappeared. Journal of Historical Pragmatics 6. 1-35.

Lightfoot, David. 1991. How to set parameters: arguments from language change. Cambridge, MA: MIT Press.

Penka, Doris. 2006. Almost there: the meaning of almost. Proceedings of Sinn und Bedeutung 10. ZAS papers in linguistics, Nr. 44, ed. by C. Ebert and C. Endriss, 275-86. Berlin: ZAS.

Roberts, Ian. 2010. Grammaticalization, the clausal hierarchy, and semantic bleaching. Gradience, gradualness, and grammaticalization, ed. by Elizabeth C. Traugott and Graeme Trousdale, 45-73. Amsterdam: Benjamins.

- , and Anna Roussou. 2003. Syntactic change: a minimalist approach to grammaticalization. Cambridge: Cambridge University Press.

Traugott, Elizabeth C. 1988. Pragmatic strengthening and grammaticalization. Proceedings of the 14th annual meeting of the Berkeley Linguistic Society, ed. by S. Axmaker, A. Jaisser and H. Singmaster, 406-16. Berkeley: Berkeley Linguistic Society.

. 2006. The semantic development of scalar focus particles. The handbook of the history of English, ed. by Ans van Kemenade and Bettelou Los, 335-59. London: Blackwell.

- and Richard B. Dasher. 2002. Regularity in semantic change. Cambridge: Cambridge University Press.

Zeevat, Henk, , and E. Karagjosova. 2009. The history and grammaticalization of "doch"/"toch". ZAS papers in linguistics Nr. 51, Berlin: ZAS.

\section{Source Texts}

Das Bonner Frühneuhochdeutsch-Korpus. $18^{\text {th }}$ Aug. $2010<$ http://www.korpora.org/fnhd/>.

Laube, A., and U. Weiss (eds). 1997. Flugschriften gegen die Reformation (1518 - 1524). Berlin: Akademie Verlag. $20^{\text {th }}$ Aug. $2010<$ http://books.google.de $>$.

Wittenwiler, Heinrich. (c. 1408/10). Der Ring, Part I "Die Brautwerbung”. Quoted after Bibliotheca Augustana. $20^{\text {th }}$ Aug. $2010<$ http://www.hs-augsburg.de/ harsch/germanica $>$.

\section{Search Covered}

Altdeutsche Predigten I, Obersächsisch, Early 14. century

Benediktinerregel Oxford, Nassau 14. century

Buch Altväter, Stuttgart 14. Jahrhundert

Das Buch der Cirurgia des Hieronymus Brunschwig. Straßburg, 1497

Des Gottesfreundes im Oberland (= Rulmann Merswin's) Buch von den zwei Mannen. Nach der ältesten

Strassburger Handschrift 1352

Gerold Edlibach: Chronik, Zürich 1485-1486

Gualtherus Burlaeus: Das Bu ${ }^{\circ}$ ch von dem Leben und Sitten der heydnischen Maister, Augsburg 1490

Handschrift Pillenreuth Mystik, Nürnberg 1463

Hans Mair: Troja, Nördlingen 1392

Hans Neidhart: Eunuchus des Terenz, Ulm 1486

Helene Kottanerin: Denkwürdigkeiten, Wien 1445-1452

Johannes Rothe: Chronik, Thüringisch second half, 15. century

Johannes Tauler: Sermon des grosz gelarten, in Gnade erlauchte Doctoris Johannis Thauleri Predigerr Ordens,

Leipzig 1498

Johann Wonnecke von Cube: Hortus Sanitatis, Mainz 1485

Mönch von Heilsbronn: Von den sechs Namen des Fronleichnams, Nürnberg late 14. century

Naturlehre Mainau, Osthochalemannisch, late 14. century

Wilhelm Durandus: Rationale, Wien 1384

Zwei Psalter aus dem 14. Jahrhundert (Dresden MS. 287 und Hamburg in SCR. 142) und drei verwandte

Bruchstücke aus Schleiz, Breslau und Düsseldorf 